\title{
Inclusive innovation: getting more from less for more
}

\author{
Prahlad Vadakkepat ${ }^{*}$, Hari Krishna Garg, Ai Poh Loh and Ming Po Tham
}

In the age of consumerism, efforts at developing products and services have largely been focused on utilizing resources in addressing the wants and needs of people especially at the top of the economic pyramid. The products designed with sophisticated features lead to higher complexity and cost. These products do not satisfy the needs of the low-income consumers who live on an income that is less than $\$ 5$ a day (Guerrant Foundation 2014).

The consumers at the base of the economic pyramid live in environments which are geographically remote, with constrained financial resources, institutional void, and insufficient technological know-how. These contextual constraints can be turned into advantages through frugal innovation, leading to delivering quality services and products for low-income consumers. Frugal innovation helps in bringing down the cost of products without compromising on quality, by minimizing the consumption of resources during design, development, and production stages.

The prosthetic limb "Jaipur Foot" which costs $\$ 45$ is a classic example of frugal innovation. With Jaipur Foot, the wearers can squat, run, sit cross-legged, and climb trees (Bound \& Thornton 2012, Hasib 2013). Due to low-cost and non-compromised quality, the Jaipur Foot has restored dignity and mobility for over 400,000 people in Afghanistan, India, and Iraq (Kanani et al. 2011).

Science and technology are to be used judiciously for the benefit of all. Frugal products can provide greater functionality to a wider cross section of people by minimizing costs and resource consumption. Frugal innovation helps in repositioning the poor from passive recipients of donations to active consumers.

People at the base of economic pyramid are "media dark." They are denied access to services and products and are unaware of available alternatives and how to use them. Frugal innovation places affordable products and solutions in the hands of those at the base of the economic pyramid, leading to empowerment

\footnotetext{
* Correspondence: prahlad@nus.edu.sg

National University of Singapore, Singapore, Singapore
}

and improvements in their lives. The Aravind Eye Care System in India is one such solution that has touched millions of lives. About $80 \%$ of cataract blindness cases are reported in developing countries (Thulasiraj \& Rangan 2007). The social costs of blindness are high, with those affected often losing their livelihood and self-respect. Eye surgeries at private hospitals are costly, and the treatment is not affordable especially for those living at the base of the economic pyramid. The Aravind Eye Care System was founded by Dr. Venkataswamy, an Indian ophthalmologist, making cataract surgeries affordable and to eliminate the needless blindness. The Aravind eye care model performs $70 \%$ of the surgeries free of cost and could reach out to the poorest of the poor (Bound \& Thornton 2012). While the rich clients have the privilege of paying for personal rooms, the same quality eye care services are provided to the poor on a no frills basis (Bound \& Thornton 2012). Aravind eye care doctors are able to perform 3000-4000 surgeries a year through their unique service-oriented model (Mehta \& Shenoy 2011).

Making products affordable by reducing the cost does not necessarily mean simply stripping off features. For truly meaningful in the user context, the products have to be redesigned innovatively while keeping in mind the user requirements. For successful consumer adoption, the product developers have to step into the shoes of the consumers to identify the needs of the users and, to understand in depth the operational environments and associated constraints.

Interviews aid in understanding the needs that the users are aware of. For frugal innovation, it is essential to dive deeper to understand the contextual constraints which may not always be articulated by users. The contextual constraints could be associated with the cultural norms or society, the environmental constraints, and technical background. Ethnography is the technique utilized to identify user needs and requirements by observing the users in their socially established environments (Shahidi \& Kasiun 2009). 
Minimizing resource consumption makes products affordable which in turn leads to environmentally sustainable consumption. Through over consumption and wastage by the ever increasing population, the resources of Mother Earth are diminishing at an alarming rate. Frugal products can play a crucial role in ensuring that the future generations can live well while satisfying the ever increasing demands of the present generation.

Frugal innovation can be along products or services. As a process, frugal innovation reconfigures value chains, redesigns products, and discovers new business models in a scalable and sustainable manner. Examples of frugal innovation in services are along education, energy, training, banking, and communication; and, in products, examples are along housing, medical devices, and automobiles.

The Journal of Frugal Innovation (JFI) is aimed at providing a platform for facilitating timely dissemination of innovative concepts for emerging markets. JFI is an open access journal catering to the needs of a wider cross section of populace. Frugal innovation can provide products and services with extreme affordability leading to an inclusive growth.

Received: 16 October 2015 Accepted: 16 October 2015

Published online: 03 November 2015

\section{References}

Bound, K, \& Thornton, I (2012). Our frugal future: lessons from India's innovation System. Nesta. https://www.nesta.org.uk/sites/default/files/our_frugal_future.pdf Hasib, NI. "bdnews24", bdnews24, 31 July 2013. [Online]. Available: http://bdnews24.com/bangladesh/2013/07/31/all-for-a-foot

Kanani, R. Jaipur Foot: One of the most technologically-advanced social enterprises in the world, 8 August 2011. [Online]. Available: http://www.forbes.com/sites/rahimkanani/2011/08/08/jaipur-foot-one-ofthe-most-technologically-advanced-social-enterprises-in-the-world/ Mehta, PK, \& Shenoy, S (2011). In Infinite Vision. Berrett-Koehler.

Shahidi, S, \& Kasiun, Z (2009). Using ethnographic techniques in developing a mobile tool for requirements elicitation. In International Conference on Information Management and Engineering.

Thulasiraj, R, \& Rangan, V (2007). Making sight affordable. Innovations, 2, 35-49. World Income Distribution Statistics. Guerrant Foundation, 3 July 2014. [Online]. Available: http:/guerrantfoundation.org/world-income-distributions-stats/
Submit your manuscript to a SpringerOpen ${ }^{\circ}$ journal and benefit from:

- Convenient online submission

- Rigorous peer review

- Immediate publication on acceptance

- Open access: articles freely available online

- High visibility within the field

- Retaining the copyright to your article

Submit your next manuscript at $>$ springeropen.com 